\title{
Imagens do Brasil na música erudita do século XX: reflexões conceituais sobre identidades culturais brasileiras
}

\author{
Images of Brazil in the 20th-century classical music: \\ reflections about Brazilian cultural identities
}

\author{
Potiguara Curione Menezes ${ }^{1}$ \\ ${ }^{1}$ Universidade de São Paulo, São Paulo, SP, Brasil. \\ poticurione@terra.com.br
}

\section{Resumo:}

O presente artigo trata do processo de construção de imagens na elaboração da identidade cultural expressa na música erudita brasileira, durante o século XX. Para isso, buscou-se apontar algumas questões conceituais, relacionadas à narrativa, às criações de imagens e à identidade cultural, que são fundamentais para o entendimento da cultura brasileira como um sistema de representações culturais. Nesse sentido, tentamos traçar um quadro referencial (SALLES, 2005; KATER, 2001; CONTIER, 1978) de como se criaram algumas relações significativas entre determinados materiais musicais e elementos da cultura brasileira. Assim, partimos de reflexões em torno das ideias de sujeito, identidade, pertencimento, cultura e identidade nacional (HALL, 2006). Em seguida, procuramos entender o processo de construção das narrativas e imagens em torno de uma identidade cultural nacional, para, só então, compreender a relatividade das autoimagens coletivas (REZENDE, 2009; ORTIZ, 1994) que se fizeram presentes na música erudita brasileira neste período.

Palavras-Chave: identidade cultural; cultura brasileira; música contemporânea; música brasileira 


\section{Abstract:}

This article discusses the process of image construction in the elaboration of the cultural identity expressed in the Brazilian classical music during the twentieth century. Conceptual issues related to the narrative, image creation, and cultural identity essential to the understanding of Brazilian culture as a system of cultural representations are discussed. Central references on the emergence of significant relationships between certain musical materials and elements of the Brazilian culture (SALLES, 2005; KATER, 2001; CONTIER, 1978) are outlined. Departing from the definitions of subject, identity, sense of belonging, culture and national identity, it explains the process of narrative and image construction around a national cultural identity. Finally, it aims at understanding the relativity of the collective self-images (REZENDE, 2009; ORTIZ, 1994) that have been made present in the Brazilian classical music in that period.

Keywords: cultural identity; Brazilian culture; contemporary music; Brazilian music

Data de recebimento: 03/12/2014

Data de aprovação final: 20/09/2015

\section{1 - Usos e concepções de elementos da cultura brasileira na música do século XX}

Sabemos que, desde meados do século XIX, muitos compositores se apropriaram e empregaram elementos culturais brasileiros, étnicos e populares, transformando-os em materiais musicais. Neste percurso, estes criadores conceberam tais referências com intenções e maneiras distintas. Porém, o que viria a ser um elemento musical pertencente à cultura brasileira, é uma indagação que depende de uma série de fatores para ser compreendido. Para nortear um discurso sobre esse assunto, é preciso aclarar questões como: Que tipo de manifestação e que tipo de música concede a um elemento esta qualidade? Ser produzido no Brasil ou por autor brasileiro? Ser popular? Ter suas origens no nosso país? Haver sido produzido por etnias consideradas fundadoras da nossa cultura? 
Conceitualmente, a questão principal que se coloca, por detrás das indagações feitas acima, é o tema da identidade cultural. Neste sentido, faz-se necessário abordar tal conceito com o intuito específico de orientar uma discussão de foro musical. Assim, proporemos algumas inquisições que servirão de guia para o entendimento deste tópico: O que, quem e/ou como se define um elemento como culturalmente brasileiro? Como foram criadas tais definições? Estas características são fixas? Existe uma cultura brasileira única?

Responder satisfatoriamente questões deste tipo não é tarefa fácil e demandaria reflexões teóricas demasiado profundas, para além do que seria possível neste artigo. No entanto, queremos apontar aspectos fundamentais para o entendimento da construção de imagens da cultura nacional. Tais aspectos estão associados ao emprego dos elementos musicais, considerados portadores de brasilidade, por determinados compositores.

Vários autores vêm abordando e discutindo extensamente o tema da identidade cultural, dentro das correntes da teoria social. Vamos encontrar, fora do Brasil, nomes como Stuart Hall, Zygmunt Bauman, Benedict Anderson, Homi Bhabha, Ernest Gellner, Anthony Giddens, Richard Handler, Judith Butler, Craig Calhoun, Nestor Canclini e Anthony Smith - para citar apenas alguns. No plano nacional, Darcy Ribeiro, Renato Ortiz, Carlos Mota e Claudia Rezende - entre outros - são referências importantes para qualquer argumentação relacionada ao tema. Particularmente, três livros - por oferecerem uma visão panorâmica sobre o assunto - nos guiarão na explanação dos conceitos-chave que iremos trabalhar: $A$ identidade cultural na pós-modernidade (HALL, 2006), Retratos do estrangeiro (REZENDE, 2009) e Cultura brasileira e identidade nacional (ORTIZ, 1994).

Tendo em vista as observações acima, trataremos, de forma breve, dos processos de construção das narrativas e imagens relacionadas a uma identidade cultural nacional. Para isso, começaremos com uma curta explanação dos conceitos de sujeito, identidade e pertencimento. Em seguida, partiremos para a conceituação da cultura nacional. Por fim, chegaremos à questão-foco deste artigo, que é relacionar a construção da identidade cultural brasileira com o imaginário musical em torno dela no decorrer do século XX. 


\title{
2 - Os conceitos: sujeito, identidade, pertencimento e cultura nacional
}

\begin{abstract}
Todas as relações fixas e congeladas, com seu cortejo de vetustas representações e concepções, são dissolvidas, todas as relações recémformadas envelhecem antes de poderem ossificar-se. Tudo que é sólido se desmancha no ar... (Marx e Engels, citado por HALL, 2006, p.14)
\end{abstract}

A epígrafe enunciada por Karl Marx e Friedrich Engels, em relação à modernidade, prenunciava o processo de mudança na construção das identidades que estamos presenciando nos dias de hoje. Como denota Stuart HALL (2006):

\footnotetext{
(...) o sujeito, previamente vivido como tendo uma identidade unificada e estável, está se tornando fragmentado; composto não de uma única, mas de várias identidades, algumas vezes contraditórias ou não-resolvidas. (...) $\mathrm{O}$ próprio processo de identificação, através do qual nos projetamos em nossas identidades culturais, tornou-se mais provisório, variável e problemático. (HALL, 2006, p.12)
}

O descentramento do sujeito resultou nas identidades abertas, contraditórias, inacabadas e fragmentadas do sujeito pós-moderno. Assim, este sujeito não tem uma identidade fixa, essencial ou permanente, ao contrário, ele "assume identidades diferentes em diferentes momentos, identidades que não são unificadas ao redor de um eu coerente" (HALL, 2006, p.13). Essas identidades são constituídas e transformadas continuamente em relação às formas pelas quais somos representados nos sistemas culturais que nos rodeiam. Portanto, à medida que os sistemas de significação e representação cultural se multiplicam, nós somos confrontados por uma multiplicidade de identidades possíveis, com cada uma das quais poderíamos nos identificar - ao menos temporariamente.

Neste sentido, referindo-se a diversos autores - como J. Butler, C. Calhoun, Dorinne Kondo e o próprio S. Hall - a antropóloga Claudia REZENDE (2009) argumenta que "a identidade vem sendo tratada geralmente, na literatura das ciências sociais, como planos de identificação que são construídos continuamente - e não dados a priori - desempenhados de acordo com os vários contextos de interação, sempre em transformação" (REZENDE, 2009, p.19). A identidade é realmente um elemento formado, ao longo do tempo, através de processos inconscientes, e não um elemento inato. Portanto, "existe sempre algo imaginário 
ou fantasiado sobre sua unidade. Ela [a identidade] permanece sempre incompleta, está sempre em processo, sempre sendo formada" (HALL, 2006, p.38).

REZENDE (2009, p.19-20) aponta ainda que, apesar da diversidade de enfoques, há dois aspectos fundamentais, relativamente consensuais, para compreender como a identidade gera pertencimento. $\mathrm{O}$ primeiro seria a relação de unidade e semelhança de um sujeito com determinado grupo social, por contraste com os outros grupos. "Definir quem é uma pessoa implica definir quem ela não é." Assim, a identidade é colocada como uma ocorrência "relacional e contrastiva". Neste sentido, Roberto Cardoso Oliveira (citado por REZENDE, 2009, p.21) enfatiza "o caráter frequentemente latente das identidades étnicas, que só se manifestam em situações de contraste, o que também é comum às identidades nacionais”. $O$ segundo aspecto seria o reconhecimento - tanto pelo grupo afim quanto por outros - desta relação de pertencimento criada pelo sujeito. Portanto, a identidade opera de maneira fundamental nestas duas esferas da vida social, a experiência individual e o pertencimento a grupos sociais.

Para nós, é importante destacar estas duas maneiras de elaboração do vínculo de pertencimento do sujeito ao grupo, pois elas estão entre os principais processos envolvidos na formação das identidades nacionais. Esta sensação de pertencimento está ligada diretamente ao modo como este sujeito irá criar seu sistema de representações, que definirá as atribuições dadas por ele aos objetos ao seu redor. Autores como Katherine Verdery e Michael Herzfeld - citados por Claudia REZENDE (2009, p.73-74) - apontam a existência dessa "subjetividade nacional" no processo de construção individual dos significados do que é ser nacional. Tais afirmações nos ajudam a lembrar que, para um elemento musical ser considerado como parte integrante da cultura brasileira, é necessário que um indivíduo e/ou um grupo considere-o como tal.

As manifestações de nossas identidades culturais podem se dar em muitas instâncias e surgem, principalmente, da sensação de "pertencimento a culturas étnicas, raciais, linguísticas, religiosas e, acima de tudo, nacionais" (HALL, 2006, p.8). Dessa forma, a identidade nacional é uma destas instâncias da identidade cultural. 
Segundo REZENDE (2009, p.21), o pertencimento a uma comunidade política é um dos elementos-chave da identidade nacional e traz consigo duas questões. A primeira é a ideia de pertencimento como algo consciente. Citando Smith e Hroch, a autora assinala que a consciência de integrar uma comunidade política, com direitos e deveres comuns a todos, faria parte de qualquer identidade ou movimento nacional. A outra questão é o caráter diferencial advindo da noção de "partilhar experiências em função de pertencer a uma nação", em oposição aos que não pertencem a ela. Woodward, Anderson e Verdery são mencionados por REZENDE (2009, p.22), para mostrar a importância dessa cumplicidade. Novamente colocam-se, aqui, os dois aspectos relacionais e contrastivos da identidade, citados anteriormente.

Conforme essa breve argumentação apresentada, vimos que as identidades não são características com as quais nós nascemos, elas são, sim, "formadas e transformadas no interior das suas representações" (HALL, 2006, p.48). De acordo com o raciocínio deste autor, nós só sabemos o que significa ser brasileiro, por exemplo, devido ao modo como a brasilidade veio a ser representada — como um conjunto de significados — pela cultura do país.

\footnotetext{
A nação não é apenas uma entidade política, mas algo que produz sentidos - um sistema de representação cultural. As pessoas não são apenas cidadãos(ãs) legais de uma nação; elas participam da ideia da nação tal como representada em sua cultura nacional. (HALL, 2006, p.48-49)
}

As culturas nacionais atuam tanto como uma fonte de significados culturais, quanto como um foco de identificação e um sistema de representação.

\begin{abstract}
As culturas nacionais são compostas não apenas de instituições culturais, mas também de símbolos e representações. Uma cultura nacional é um discurso - um modo de construir sentidos que influencia e organiza tanto nossas ações quanto a concepção que temos de nós mesmos (...). Esses sentidos estão contidos nas estórias que são contadas sobre a nação, memórias que conectam seu presente com seu passado e imagens que dela são construídas. Como argumentou Benedict Anderson (1983), a identidade nacional é uma comunidade imaginada. (Anderson, citado por HALL, 2006, p.50)
\end{abstract}

Essas comunidades imaginadas são perpetuadas pela memória do passado e pelo desejo de viver em conjunto. Porém, "as nações, tais como as narrativas, perdem suas origens nos mitos do tempo e efetivam plenamente seus horizontes apenas nos olhos da mente" (Bhabha, 
citado por HALL, 2006, p.51). A frase de Homi Bhabha aponta para a relatividade da ideia de nação, reforçando a hipótese de Hall de que as culturas nacionais "são atravessadas por profundas divisões e diferenças internas, sendo unificadas apenas através do exercício de diferentes formas de poder cultural" (HALL, 2006, p.62). Neste sentido, para o autor, as nações modernas são verdadeiros híbridos culturais (sic).

Para finalizar a conceituação da cultura e da identidade nacional, é necessário reafirmar que ocorre, na atualidade, uma desconstrução da ideia de cultura nacional como identidade unificadora. "As identidades nacionais foram uma vez centradas, coerentes e inteiras, mas estão sendo agora deslocadas pelos processos de globalização" (HALL, 2006, p.50).

\section{3 - Narrativas nacionais e a construção de identidades culturais}

O próximo ponto a ser discutido é a maneira como se formam estes sistemas de representação e pertencimento que definem as identidades nacionais. Como é contada a narrativa da cultura nacional?

REZENDE (2009) e HALL (2006) apontam vários aspectos que constituem esta narrativa e têm pontos em comum em suas respostas a estas indagações. $\mathrm{O}$ aspecto principal dessa confluência seria o fato de que as noções de cultura e história (partilhadas por todos) carregam, em geral, visões homogeneizantes e essencialistas dessa cultura comum. Elas tendem a ofuscar a diversidade cultural e social existente no interior de qualquer nação através da criação e disseminação de uma autoimagem coletiva.

Nesse sentido, Hall apresenta-nos cinco exemplos de como são contadas tais narrativas nacionais, todos eles relacionados de algum modo com o ideal aglutinador descrito acima:

1) O primeiro refere-se à formação de imagens comuns através da literatura e história nacional, mídia e cultura popular, conferindo à existência dos sujeitos "um destino nacional que preexiste a nós e continua existindo após a nossa morte” (HALL, 2006, p.52). 
2) O segundo exemplo está relacionado à intemporalidade e refere-se à ênfase em representar a identidade nacional como algo primordial, tradicional, unificado, contínuo e imutável.

3) O terceiro é a constatação de uma estratégia discursiva que, segundo HALL (2006), foi denominada invenção da tradição, pelos historiadores Eric Hobsbawm e Terence Ranger.

\footnotetext{
Tradições que parecem ou alegam ser antigas são muitas vezes de origem bastante recente e algumas vezes inventadas... Tradição inventada significa um conjunto de práticas..., de natureza ritual ou simbólica, que buscam inculcar certos valores e normas de comportamentos através da repetição, a qual, automaticamente, implica continuidade com um passado histórico adequado. (HALL, 2006, p.54)
}

4) O mito fundacional é o quarto exemplo de narrativa da cultura nacional dado pelo autor. Trata-se de "uma estória que localiza a origem da nação, do povo e de seu caráter nacional num passado tão distante que eles se perdem nas brumas do tempo, não do tempo real, mas de um tempo mítico" (HALL, 2006, p.54).

5) O quinto - e último caso descrito - é de caráter simbólico e utiliza como base para a narrativa da nação a crença na existência de um povo (folk) puro original (sic) originário daquela pátria.

REZENDE (2009) acrescenta a este quadro referencial que a elaboração das imagens coletivas associadas à identidade de um tipo nacional, geralmente, estão vinculadas a elementos de gênero e raça. Há uma preleção por determinadas características - corporais ou raciais - ou a adoção da mistura racial como narrativa da nação brasileira ou ainda a eleição de uma imagem tipificada como representante do sujeito nacional.

Os argumentos apresentados até aqui nos mostraram alguns mecanismos de construção da ideia de nação, como comunidade imaginada, e das identidades nacionais através das estratégias de narrativas nacionais. Esses argumentos, muitas vezes, implicam a criação de estereótipos. A persistência e adesão a estas imagens tipificadas acontecerão, em maior ou menor grau, dependendo do sujeito e do contexto onde se manifestem as identidades em questão. Contudo, coloca-se aqui uma nova inquietação: como se manifesta a identidade nacional no sujeito pós-moderno? 
Tendo em mente as características relacionais e contrastivas da identidade, apontadas no decorrer deste trabalho, nota-se que sua manifestação torna-se mais visível em situações de contraste, no confronto entre grupos nacionais distintos. "Nestes contextos, as pessoas frequentemente recorrem a estereótipos do outro, tendo também que lidar com as imagens tipificadas de si mesmo, apresentadas pelos outros..." (REZENDE, 2009, p.74).

Em seu livro, a referida autora - citando também outros estudos similares - discorre sobre a utilização de estereótipos, quando brasileiros que viveram no exterior são solicitados a descrever suas brasilidades. As referências aos hábitos alimentares e às comidas - como a feijoada, o café, o pão de queijo e o churrasco - à afetividade e ao caráter festeiro dos brasileiros foram pontos comuns no discurso dos indivíduos estudados.

Da forma similar, buscaremos, em seguida, avaliar em que medida estão presentes elementos tipificados ou estereotipados - bem como a existência de traços comuns - na representação e utilização dos elementos da cultura brasileira pelos(as) compositores(as) em suas obras. No entanto, mesmo que “(...) a definição de brasilidade passe, em geral, por símbolos nacionais e outros estereótipos (...)", ela "não escapa de ser tingida por um sentimento ambivalente", pois há uma negociação dessas imagens no processo de elaboração identitária, uma "subjetividade nacional". Portanto, "se há um imaginário acerca do que significa ser brasileiro, ele é manipulado, com alguma variação, pelas pessoas, que constroem assim um sentido de pertencimento à nação, de modo não tipificado, com características individuais" (REZENDE, 2009, p.75).

\section{4 - Uma visão musical das narrativas sobre a identidade cultural brasileira}

Chegamos assim ao ponto nevrálgico deste artigo. Se, antes, estávamos discutindo a maneira como é contada a narrativa da cultura nacional, queremos, agora, ir ao encalço das expressões desses aspectos no âmbito musical brasileiro no século XX. Sem muitas pretensões, tentaremos trazer para o universo da música os conceitos explorados na seção 
anterior. Primeiramente, retornaremos às questões levantadas no início deste texto - sobre as definições de relação entre elementos musicais e cultura brasileira - para elucidar alguns pontos. Em seguida, apresentaremos um pequeno painel histórico das aparições desses aspectos na composição musical no decorrer do século $\mathrm{XX}$, buscando relacionar as estratégias de narrativa e os processos envolvidos na formação de um ideal de identidade cultural brasileira com as recorrências musicais de certos símbolos criados neste período.

Vejamos o primeiro ponto ao qual nos referíamos: definir um elemento musical como culturalmente brasileiro continua uma indagação carente de resposta objetiva. Vimos que uma resposta convincente passaria pelo entendimento da construção fragmentada e subjetiva da identidade do sujeito pós-moderno e que a definição de uma cultura nacional não é fixa e definitiva, mas construída continuamente de acordo com as narrativas a seu respeito. Nesse sentido, o sociólogo e antropólogo Renato ORTIZ (1994) procura mostrar que a identidade nacional está profundamente ligada a uma reinterpretação do popular pelos grupos sociais e à própria construção do Estado brasileiro. Não existe, assim, uma identidade autêntica, mas uma pluralidade de identidades, construídas por diferentes grupos sociais, em diferentes momentos históricos.

Tendo em vista a complexidade e o caráter abstrato dos conceitos envolvidos na definição da cultura e identidade nacional no Brasil, apresentaremos, a seguir, alguns exemplos de relação entre as narrativas em torno desta identidade e a criação de símbolos musicais brasileiros. O intuito desta exemplificação é compreender historicamente o surgimento de alguns símbolos e estereótipos musicais, consensualmente, tidos como nacionais. Para isso, utilizaremos os cinco exemplos de estratégias narrativas na construção de imagens, apontados por Stuart HALL (2006).

O primeiro aspecto narrativo de construção de imagens comuns numa cultura nacional, denotado por Hall, refere-se ao papel da literatura e história oficial do país, mídia e cultura popular. Tomemos como exemplo a mídia de um determinado momento histórico do Brasil (meados do século XX). O compositor e musicólogo Mauricio DOTTORI (2005) destaca o papel fundamental da indústria fonográfica e do rádio na formação de uma visão comum do país - através da difusão em massa da canção brasileira. O autor assinala a influência musical 
nas representações que nós, brasileiros, temos de certas regiões do país, como a música de Dorival Caymmi na imagem da Bahia; a bossa nova e o samba carioca no ideário sobre o Rio de Janeiro; e o baião na representação da região nordeste. "Estados brasileiros que não participaram deste projeto de construção musical da nacionalidade (como o Paraná ou o Espírito Santo) não pertencem ao imaginário brasileiro" (DOTTORI, 2005, p.114).

A ênfase na tradição, continuidade e intemporalidade, contida no segundo exemplo do antropólogo jamaicano (Hall), pode ser encontrada na adoção do folclore como expressão máxima da brasilidade pelo nacionalismo musical. A ausência de um compositor, e, portanto, de uma origem determinada, da manifestação folclórica abraça a ideia de representar a identidade nacional como algo primordial, tradicional, unificado, contínuo e imutável. Da mesma forma, o destaque (por estas correntes teóricas) da ancestralidade rítmica afro, atribuída à música urbana da primeira metade do século passado $(\mathrm{XX})$ - como o maxixe, o tango brasileiro, o choro, e, posteriormente, o samba -, dilui suas origens num tempo imemorial.

A terceira estratégia discursiva descrita é a invenção da tradição. Um exemplo deste aspecto é a ideia, muito difundida, de que o samba é algo que sempre foi tradicional na cultura brasileira. Esse argumento é falso e traz consigo duas questões. A primeira é que ele é uma manifestação urbana recente, datada do século XX e, portanto, tem apenas cerca de cem anos. A outra diz respeito à sua ocorrência, geograficamente localizada, e sua fundação étnica. $\mathrm{O}$ samba tem suas origens na música negra do Rio de Janeiro e da Bahia. No entanto, ao ser considerado como símbolo nacional, ele perde sua especificidade de origem e torna-se um elemento unificador de nossa cultura. O livro O Mistério do Samba, de Hermano Viana (2010), aprofunda bastante esta questão e demonstra a trajetória de conversão do samba em símbolo nacional.

O mito fundacional é o quarto exemplo de forma narrativa das nações, no livro de Stuart HALL (2006). Para exemplificar esta estratégia de narração, observemos o mito das três raças. ORTIZ (1994) aponta que, na virada do século XIX para o século XX, surge a “fábula das três raças" - como apresentada pelo antropólogo Roberto da Matta. Contudo, parece ser mais preciso considerar essa fábula como mito, pois, tal como ocorre nas sociedades 
primitivas, ela é um mito cosmológico e conta a origem do moderno Estado brasileiro. $\mathrm{O}$ texto a seguir - de Darcy RIBEIRO (1992) - traça um paralelo entre o sujeito nacional do período colonial e do moderno (ou pós-moderno), descrevendo uma tipologia física comum aos brasileiros, tanto os de ontem como os de hoje (sic), baseada nas raças consideradas como formadoras de nossa cultura. Apresenta-se, desta maneira, uma origem da identidade étnica e cultural da nação num tempo que se aproxima da ideia de tempo mítico, referido por Hall.

\begin{abstract}
O brasileiro é aquele que se assume como brasileiro para deixar de ser ninguém. É filho da índia prenha por um branco, que não se identifica com seu gentio materno, subjugado e subalterno, mas também não é aceito como igual pelo gentio paterno, que o vê como filho da terra, bastardo e espúrio.

É mulato, parido por uma negra prenhada pelo amo ou pelo capataz, que não quer ser negro, por ser mais claro e por rejeitar a condição servil da mãe, mas não é visto como igual pelos brancos, nem sequer, como gente verdadeira. Esses mestiços mulatos, Zé-ninguéns, já não sendo índios, nem afros, nem europeus, caem no vazio do não ser, de que só podem escapar assumindo outro ser, outra identidade, a de brasileiro.

Brasileiro é, pois, esta gente nativa mestiça, sobrante e indesejada, que irrompe na sociedade colonial, partida entre senhores e escravos, como uma entidade nova e intrusa. A imensa maioria destes brasileiros, tanto os de ontem como os de hoje, tidos como brancos, deixa ver, nas feições, a marca de sua origem indígena; se morenos, sua ancestralidade africana. (RIBEIRO, 1992, p.32 - grifo nosso)
\end{abstract}

O quinto exemplo de aspectos da narrativa nacional pauta-se na criação de um povo (folk) puro original, de caráter simbólico. Esta entidade representaria a etnia primordial da nação. No nosso caso, temos a figura do índio, apesar das diferentes representações nos diversos momentos da nossa história. Já desde o romantismo brasileiro, temos, na chamada fase indianista, a figura indígena representada na obra de diversos autores, como José de Alencar, na literatura, e Carlos Gomes, na música. Porém, esta personagem aparece de forma fantasiosa numa busca pela sua europeização civilizatória e não se reflete sonoramente, através da incorporação de elementos musicais indígenas. Posteriormente, durante o nacionalismo modernista, a imagem indígena retorna, mas com um novo enfoque. Foi atribuído a esta figura um caráter de entidade germinal de nossa terra-mãe - juntamente ao elemento negro - através da reinterpretação do mito das três raças. Embebidos nestes ideais, alguns compositores buscaram fontes etnográficas da época para incorporar elementos musicais indígenas em suas obras. São muitos os exemplos musicais em que se ouvem melodias e ritmos de origem indígena na música de Villa-Lobos e demais compositores. Esta 
imagem de brasilidade musical exótica foi amplamente difundida na França durante a década de 1920 pela obra de Villa e por autores como Darius Milhaud.

\title{
5 - Pequeno panorama das imagens do Brasil na música erudita do século XX
}

Agora que já observamos algumas das maneiras como as narrativas em torno da nação podem se refletir em imagens musicais, atenhamo-nos à questão de como se formaram e se manifestaram as questões de brasilidade na música erudita brasileira, no decorrer do século $\mathrm{XX}$.

Para responder a esta indagação e contextualizar esta pesquisa, delineou-se um pequeno painel histórico das inserções de material relacionado à cultura nacional e/ou popular, na composição musical. Buscaremos pinçar pontos fundamentais onde as narrativas em torno da identidade nacional expandiram-se para o âmbito musical erudito no Brasil.

\begin{abstract}
Desde o final do romantismo, a representação musical de elementos da cultura brasileira surgiu em obras de diversos compositores, com procedimentos e técnicas derivados de diversas correntes e estilos musicais. Críticos e musicólogos abordaram questões sobre o nacionalismo musical e a vanguarda cosmopolita. Manifestos e cartas foram publicados e discutidos. Até há poucos anos, ainda se fazia presente a oposição veemente entre esses dois partidos de militância. Ambos devidamente policiados ideologicamente pelos parâmetros respectivos de cada corrente. Ao início do século XXI a querela se dissolveu, talvez diante de uma outra questão, o desinteresse da sociedade pela música contemporânea de concerto. (João Marcos Coelho, citado por MARTINEZ, 2006, p.1)
\end{abstract}

Na música brasileira de meados do século XIX, já se observam representações da cultura brasileira. Segundo a musicista, jornalista e escritora Léa FREITAG (1985), tal fenômeno já havia sido prenunciado, no período do Império, com a nacionalização da ópera por autores como Francisco Manuel da Silva (1795-1865) e Carlos Gomes (1836-96). Neste sentido, o historiador Arnaldo CONTIER (1978) denota o processo gradativo de rompimento com a temática religiosa e o crescimento das modinhas e lundus na primeira metade do século XIX, 


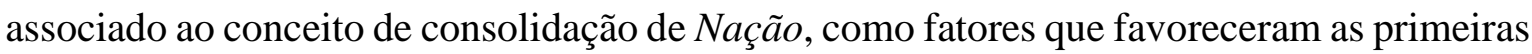
intenções de expressar a brasilidade na música.

Podemos apontar alguns compositores entre os mais representativos do período que antecede o nacionalismo brasileiro. Tais autores demonstram em suas composições um reflexo das correntes dos principais polos artísticos europeus: França, Alemanha e Itália. São eles: Henrique Oswald (1852-1931), de linguagem musical afrancesada, mas também influenciada por Brahms e Lisz, Leopoldo Miguez (1850-1902), com influências wagnerianas e Glauco Velásquez (1884-1914), de raízes italianas.

Alguns musicólogos apontam A Sertaneja (1860-69) de Basílio Itiberê da Cunha (1848-1913) como uma das primeiras obras que inserem elementos da cultura popular brasileira em sua confecção, pela utilização do "fandango sulino" Balaio (RS) como tema central da peça. Porém, existem outras peças anteriores que se utilizaram de elementos da cultura popular, como a peça para piano O Amor Brasileiro, de 1819, do compositor austríaco Sigismund von Neukomm (1778-1858) - radicado no Rio de Janeiro até meados dos anos 1820. Tal composição foi inspirada num lundu brasileiro, bastante popular na época. No entanto, todo esse período anterior ao nacionalismo modernista foi ainda muito influenciado pelo romantismo, tanto musical, quanto literário. Nomes como Gonçalves Dias e José de Alencar adaptaram modelos europeizantes a elementos nacionais, como por exemplo, na caracterização da figura do índio brasileiro. Tratava-se de mais uma tentativa de promover o elemento nativo a símbolo nacional.

Nesse contexto, surgiram também Alexandre Levy (1864-1892) e Alberto Nepomuceno (1864-1920), músicos que continuaram com esse processo de busca por uma identidade composicional brasileira em suas obras. Simultaneamente, delineava-se uma corrente de pensamento preocupada com a problemática da identidade nacional. Os precursores das Ciências Sociais no Brasil, ao final do século XIX e início do XX, Silvio Romero, Nina Rodrigues e Euclides da Cunha, apresentaram um conjunto de teorias que teria contribuído para a superação do movimento romântico, com grande impacto junto à intelligentsia brasileira: "o positivismo de Comte, o darwinismo social e o evolucionismo de Spencer"; 
teorias que em linhas gerais podem ser consideradas sob a ótica do aspecto da "evolução histórica dos povos" (ORTIZ, 1994).

Numa pequena digressão, poderíamos dizer que a sociologia da época atenta para a questão racial e marca a superioridade da civilização europeia como decorrente das leis naturais que orientam a história da humanidade. É assim que, nesse período de virada de século, se torna corrente a afirmação de que o Brasil se constitui através da fusão de três raças - o branco, o negro e o índio - mas com um viés claramente racista, dando maior importância à raça branca. Atestando tal ideia, segundo Nina Rodrigues (citada por ORTIZ, 1994), a absorção incompleta de elementos católicos pelos cultos afro-brasileiros demonstra uma incapacidade de assimilação da população negra dos elementos vitais da civilização europeia. Assim, emergiu a necessidade de se destacar o elemento mestiço, que representaria um ponto de equilíbrio. Daí surgiu a elaboração de uma identidade nacional, em que a mestiçagem moral e étnica possibilita a aclimatação da civilização europeia nos trópicos.

Retomando a veia musical, concluímos que as primeiras representações das narrativas em torno da identidade cultural brasileira, em termos musicais, se deram através "de um trabalho composicional caracterizado pelo emprego de temas (quase sempre melódicos) da música popular, temas que eram tratados segundo métodos harmônicos e polifônicos europeus" (NEVES, 1981, p.19). Essa subalternidade do elemento nativo à estrutura europeia está ligada, em parte, à visão intelectual da época citada. É preciso ter em mente a influência que a imagem da Belle Époque francesa teve sobre esta sociedade brasileira como um todo.

Assim sendo, tal contexto influenciou também a geração seguinte de compositores, que inclui nomes como Luciano Gallet (1893-1931), Lorenzo Fernandez (1897-1948) e Francisco Mignone (1897-1986), entre outros. Porém, neste período, as maiores transformações na música virão de Heitor Villa-Lobos (1887-1959), o compositor brasileiro mais conhecido até hoje: "as inovações da linguagem de Villa-Lobos estendem-se a diferentes áreas da criação, sejam elas afetas aos meios expressivos, às formas de elaboração ou à fatura específica do próprio discurso musical” (KATER, 2001, p.33-34). 
Para entender melhor alguns matizes na formação dos símbolos nacionais criados durante o movimento nacionalista, faremos outra digressão sobre o pensamento social no Brasil da primeira metade do século XX. Já dissemos que a fábula das três raças surgiu no final do século XIX. No entanto, foi somente após a transformação da negatividade racista da imagem do mestiço (contida na visão de autores como Silvio Romero e Nina Rodrigues) em positividade (segundo autores como Gilberto Freyre e Mário de Andrade) que o mito das três raças torna-se plausível, disseminando-se nacionalmente e possibilitando a delineação de novos contornos de uma identidade nacional. Esse mito, ao se difundir na sociedade, permite aos indivíduos das diferentes classes sociais e dos diversos grupos étnicos interpretar, dentro do padrão proposto, as relações raciais que eles próprios vivenciam. Contudo, na medida em que a sociedade se apropria das manifestações de um grupo étnico específico, integrando-as à unicidade nacional, elas perdem sua especificidade e esse impasse denota a ambiguidade da sociedade brasileira ao se considerar a construção de uma identidade nacional mestiça. Assim, se, por um lado, o mito das três raças "encobre os conflitos raciais", por outro "possibilita que todos se reconheçam como nacionais" (ORTIZ, 1994, p.44).

Musicalmente, o mito das três raças terá algumas implicações. A principal delas é a valorização do popular. Como aponta o compositor e musicólogo Paulo de Tarso Salles, isto estaria em conformidade com "a tradição sociológica de explicar a realidade brasileira pelo aspecto racial...” (SALLES, 2005, p.145). Por conseguinte, a apropriação por parte dos compositores de elementos advindos do folclore, das culturas indígenas e afro-brasileiras se tornará uma marca da música nacionalista.

\footnotetext{
O modernismo paulista se não é propriamente nostálgico quanto ao ruralismo, assim será em relação ao mito das três raças, vistas fora do ambiente opressor de São Paulo. As pesquisas folclóricas irão se voltar para as regiões Nordeste e Norte em busca de manifestações mais puras, que se possam desvincular da cruel justaposição do expansionismo urbano. Nessas regiões, ainda é possível encontrar sociedades intactas, nas quais as tradições mantêm-se de acordo com as relações de poder político firmemente estabelecidas (o chamado coronelismo). A estética nacionalista irá então eleger a música folclórica (que Mário de Andrade chamava de popular) como verdadeira expressão sonora do povo brasileiro. (SALLES, 2005, p.146)
}

Na década de 1920, o projeto do nacionalismo musical - que tinha como um de seus defensores mais fortes o nome de Mário de Andrade - passaria a exercer total influência sobre os compositores brasileiros. José Miguel Wisnik nos dá uma boa visão dos propósitos 
deste movimento: "sintetizar e estabilizar uma expressão musical de base popular, como forma de conquistar uma linguagem que concilie o país na horizontalidade do território e na verticalidade das classes (...)" (WISNIK, 2004, p.148). O próprio Andrade (citado por CONTIER, 1978, p.6) aponta, neste período, cinco princípios norteadores do modernismo musical brasileiro:

1) O dever composicional de fundamentação no folclore, já que as músicas folclóricas representariam os anseios do povo. Juntamente a este princípio, vê-se a opção pela música pura em negação à música de programa romântica;

2) A maneira com que o compositor deve "sentir" o inconsciente coletivo presente nestas manifestações deve seguir três processos: o emprego integral da melodia folclórica, a modificação parcial desta e, finalmente, a criação de uma melodia própria de caráter folclórico;

3) A técnica de composição deve ser o contraponto (neoclassicismo);

4) Utilização de instrumentos folclóricos na instrumentação;

5) No plano formal, "a substituição das formas clássicas pelas das formas existentes no folclore brasileiro" (sic) (Andrade, citado por CONTIER, 1978, p.6).

Como bem denota a autora Tânia Mara Lopes Cançado, entende-se que "a síncope característica desenvolvida nas Américas não tem relação com a antiga síncope europeia" (CANÇADO, 2000, p.6). Apesar de não haver consenso sobre sua origem exata, Cançado também aponta que aceita-se incontestavelmente a matriz africana da figuração de síncopa na música brasileira. Nesse sentido, Salles aponta "a presença do elemento africano na música brasileira" como o "aspecto mais enfatizado pelos teóricos do nacionalismo, principalmente pela rítmica" (SALLES, 2005, p.203) e demonstra sua colocação citando Mário de Andrade:

\footnotetext{
O africano tomou parte vasta na formação do canto popular brasileiro. Foi certamente ao contato dele que nossa rítmica alcançou a variedade que tem, uma das nossas riquezas musicais... (Andrade, citado por SALLES, 2005, p.203)
}

Se podemos notar que, desde a primeira metade do século XIX, o lundu e a modinha brasileira (pós-portuguesa) já tinham eleito a síncope como uma de suas características, no entanto, a associação da rítmica afro-brasileira à música popular só se estabeleceu mais 
intensamente, como um conceito-chave de identificação, a partir do início do século XX. Ritmos como o maxixe, o choro ou o tango brasileiro (oriundo da polca) e posteriormente o samba se consagraram como expressão máxima desta ideia. Em razão disso, desde as primeiras aparições de temas de origem popular na música erudita brasileira, a síncope supramencionada veio ganhando destaque na produção dos compositores - desde Neukom, passando por Nepomuceno, até Villa-Lobos, entre outros. Desta maneira, tornou-se uma espécie de tradição o uso sistemático e estilizado da síncope afro-brasileira, associada aos ritmos populares como o samba, o maracatu, a congada, o frevo e os temas do ritual do candomblé. Nesse sentido, Paulo de Tarso nos fornece uma excelente afirmação:

\footnotetext{
Assim, a crescente valorização da música popular tendeu a enfatizar a rítmica sincopada até o ponto em que o próprio Mario de Andrade chegou a manifestar preocupação com o que já ameaçava se tornar um maneirismo. (SALLES, 2005, p.203)
}

Contudo, Villa-Lobos é apontado pelo estudioso alemão Manuel Negwer como "um dos primeiros compositores que se aproximaram da música afro-brasileira sem intenções políticas ou etnológicas" atraído predominantemente pelas "dimensões estéticas e a utilização em suas composições como um material novo nunca empregado" (NEGWER, 2009, p.71).

A partir dos anos 30, o Estado Novo ajudou fortemente a disseminar os ideais nacionalistas. Nessa época, despontaram compositores como Camargo Guarnieri, José Siqueira (1907-85) e Radamés Gnattali, entre outros.

Em meados dos anos 40, surgiu o movimento Música Viva. Este grupo, liderado por J. H. Koellreutter (1915-2005), foi responsável por restabelecer um ponto de contato do Brasil com as tendências da Europa, trazendo o sistema de Schönberg para cá. O movimento reunia vários autores, como Claudio Santoro, Guerra-Peixe, Edino Krieger e Eunice Katunda, desenvolvendo entre nós a técnica dodecafônica em oposição ao nacionalismo musical dominante.

Da dicotomia musical nacionalismo versus vanguarda, instaurada na década de 1950 no Brasil, paradoxalmente, surgem alguns trabalhos - como os de Luis Cosme, Santoro, Katunda e Guerra-Peixe - que buscavam "associar elementos de música popular ou 
folclórica com a técnica dodecafônica” (KATER, 2001, p.131-132). Nesse sentido, José Maria Neves (1981, p.135-136) descreve alguns pontos levantados por Santoro, GuerraPeixe e Koellreutter - no início do Música Viva - sobre as possibilidades de escrever uma música "em brasileiro". Para isso, segundo estes compositores, seria necessário libertar-se da literalidade folclórica (composição sobre citações) e orientar-se para a sua essencialidade: isolando-se certos contornos melódicos, certas cadências, certas fórmulas harmônicas e certos processos de desenvolvimento, na construção de uma gramática e sintaxe musical brasileira.

Mais tarde, surge o Música Nova, na década de 1960. A ele estavam associados nomes como Rogério Duprat (1932-2006), Gilberto Mendes (1922-), Willy Corrêa de Oliveira (1938-) e Damiano Cozzella (1928-). O grupo "objetivava atualizar e internacionalizar a música brasileira" (CONTIER, 1978, p.28). Este fato será de extrema importância, pois a partir do contato "com a pesquisa criativa desenvolvida nos diferentes países do mundo, os jovens compositores brasileiros seguirão praticando o serialismo integral, a aleatoriedade, a artetotal, a eletroacústica" (NEVES, 1981, p.147). Essas ideias se refletiram na maneira de compor de muitos autores das gerações seguintes, como Jorge Antunes, Marlos Nobre e Almeida Prado (1943-2010). Tais tendências se estenderam até meados dos anos 70 e 80, podendo ser percebidas nas Bienais de Música Contemporânea (RJ) e no Festival Música Nova (Santos/SP).

Em suma, pode-se dizer que os conflitos gerados entre as vanguardas e o nacionalismo, indiretamente, propiciaram inovações no discurso musical brasileiro. Estas mudanças só puderam ser absorvidas anos mais tarde, livrando-se das feridas geradas durante as querelas ideológicas.

Após essa breve explanação sobre a relação entre a narrativa nacional e os símbolos musicais criados no imaginário cultural brasileiro, de maneira geral, nota-se, ainda hoje, que eminentemente não só a música brasileira, mas também a imagem do Brasil no exterior é associada ao carnaval, ao samba, à capoeira, ao futebol, ao negro, ao índio, à selva, às belas mulheres e ao colorido. Fica evidente que, para o entendimento mais amplo deste fenômeno, existe uma série de fatores que só o aprofundamento da sociologia musical poderia explicar 
melhor. Constatamos, no entanto, que, de certa forma, a noção de brasilidade está sempre contaminada com essa visão estereotipada, como denotou REZENDE (2009). Portanto, não seria de se estranhar que, ao expressarmos características de nossa cultura brasileira em uma obra de arte, evoquemos, frequentemente, elementos relacionados aos símbolos criados no decorrer da história de nossa nação. Porém, haverá sempre uma subjetividade nacional em nossas identidades culturais.

\section{6 - Considerações finais}

Para tentar entender um pouco melhor as relações entre materiais musicais e as autoimagens identitárias do Brasil, tentamos traçar um pequeno panorama dos usos e das concepções de elementos da cultura brasileira na música do século XX. Para isso, primeiramente, vimos as maneiras relativizadas, fragmentadas, subjetivas e contraditórias com que se constroem as noções de sujeito, identidade, pertencimento e cultura nacional na contemporaneidade, formando sistemas de representações. Em seguida, debatemos também, a importância das narrativas nacionais na construção de imagens comuns numa cultura nacional. Por fim, observamos alguns processos de transformação de certos elementos musicais em símbolos nacionais, muitas vezes estereotipados.

Talvez, de certa forma, os estereótipos de brasilidade continuem sendo invocados no momento de se salientar uma característica supostamente brasileira. O mito das três raças nas ideias de mestiçagem e ancestralidade africana e indígena, por exemplo - e os símbolos nacionais - nas manifestações populares urbanas (como o samba, o choro e as músicas nordestinas de raiz, entre outras) - estão presentes nas visões expressas por muitos compositores em seus trabalhos. Porém, há também uma subjetividade nas concepções e nas abordagens dessas imagens tipificadas - através dos processos individualizados de manipulação e representação dos elementos nacionais e étnicos. Esse fato dá um caráter inédito à produção erudita do final do século XX e reflete também novos modos com que se processam as identidades culturais nos dias de hoje - corroborando com os apontamentos de Stuart Hall, Claudia Rezende e Renato Ortiz, que destacamos. 
Este artigo é apenas uma reflexão inicial sobre a relatividade dos conceitos de elemento cultural brasileiro e de brasilidade. É um primeiro passo na discussão a respeito das relações entre processos composicionais e a incorporação de elementos musicais e culturais na música erudita no Brasil, no correr do século XX. Doravante, busca-se ampliar o debate em torno desta problemática para além das relações estabelecidas no ideário do nacionalismo musical e nas visões estereotipadas, citadas há pouco.

Nesse sentido, a metáfora da literata Eloisa Prati dos Santos pode iluminar nossas ponderações:

\footnotetext{
Hoje em dia sabedores que somos da impossibilidade de abarcar com uma única definição nossa vasta e diversa nação, nos embrenhamos em uma busca pessoal ficcional, a partir de um ponto geográfico ou histórico e iluminamos a aventura arqueológica com nossa experiência pessoal, nossa escolha de textos e mapas, do Prata ao Xingú. (SANTOS, 2006, p.200)
}

Assim, para finalizarmos em ressonância com a autora, vale dizer que etnias e culturas múltiplas do Brasil continuam a despertar o interesse musical de compositores brasileiros. Entretanto, num mundo cada vez mais globalizado, cada sujeito há de construir sua própria identidade cultural, na babel de referências da vida na pós-modernidade.

\section{Referências}

1. CANÇADO, T.L. (2000). "O fator atrasado na música brasileira: evolução, características e interpretação”. Per Musi. Belo Horizonte: UFMG. n.2, p.5-14.

2. CONTIER, A.D. (1978). Música e Ideologia no Brasil. São Paulo: Novas Metas.

3. DOTTORI, M. (2005). "As ideias e a música: influências europeias na música brasileira". Anais do colóquio Brasil musical. Paraná: De Artes - UFPR.

4. FREITAG, L.V. (1985). Momentos de Música Brasileira. São Paulo: Nobel.

5. HALL, S. (2006). A identidade cultural na pós-modernidade. $11^{\mathrm{a}}$ ed. Rio de Janeiro: DP\&A, 2006.

6. KATER, C.E. (2001). Música Viva e H. J. Koellreutter: movimentos em direção à modernidade. São Paulo: Musa Editora; Atravez. 
7. MARTINEZ, J.L. (2006). "Brasilidade e Semiose Musical”. Revista Opus. Campinas: ANPPOM. n¹2, p.114-131.

8. NEGWER, M. (2009). Villa-Lobos: o florescimento da música brasileira. São Paulo: Martins Fontes.

9. NEVES, J.M. (1981). Música Contemporânea Brasileira. São Paulo: Ricordi Brasileira.

10. ORTIZ, R. (1994). Cultura Brasileira e Identidade Nacional. $4^{\mathrm{a}}$ ed. São Paulo: Brasiliense.

11. REZENDE, C. (2009). Retratos do estrangeiro: identidade brasileira, subjetividade e emoção. Rio de Janeiro: FGV.

12. RIBEIRO, D. (1992). A Fundação do Brasil: testemunhos 1500-1700. Petrópolis: Vozes.

13. SALLES, P.T. (2005). Aberturas e Impasses: o pós-modernismo na música e seus reflexos no Brasil (1970 - 1980). São Paulo: UNESP.

14. SANTOS, E.P. (2006). "Uma Viagem até a Brasilidade: romance pós-moderno e póscolonial e romance indianista brasileiro". Revista Letras de Hoje. Porto Alegre. v.41, n.3, p.185-200.

15. VIANNA, H. (2010). O Mistério do Samba. $7^{\mathrm{a}}$ ed. Rio de Janeiro: Zahar: UFRJ.

16. WISNIK, J.M. (2004). "Getúlio da Paixão Cearense: Villa-Lobos e o Estado Novo". In: Música: o nacional e popular na cultura brasileira. Reimp. $2^{\circ}$ ed. São Paulo: Brasiliense.

\section{Literatura recomendada}

1. ANDERSON, B. (1983). Imagined communities: reflections on the origin and spread of nationalism. London: Verso.

2. BHABHA, H. (1990). O local da cultura. Belo Horizonte: UFMG.

3. CANCLINI, N.G. (2003). A globalização imaginada. São Paulo: Iluminuras.

4. HOBSBAWM, E.; RANGER, T.O. (1983). The Invention of tradition. New York: Cambridge University Press.

5. MENEZES, P. (2011). Processos composicionais, usos e concepções de elementos da cultura brasileira em três peças do final do século XX: uma abordagem analíticocomparativa. Dissertação (Mestrado em música). Escola de Comunicação e Artes, Universidade de São Paulo (USP), São Paulo. 
6. RIPPER, J.G. (1997). "Pós-Modernismo na música Latino-americana". Revista da Sociedade Brasileira de Música Contemporânea, Goiânia, n.4, p.76-83.

7. TRAVASSOS, E. (2000). Modernismo e Música Brasileira. Rio de Janeiro: Jorge Zahar.

Notas sobre o autor

Potiguara Menezes é compositor, arranjador, instrumentista e pesquisador. Foi pesquisador visitante (Bolsa Fulbright-CAPES) nos EUA, em 2014-15. Cursa o doutorado em música na Universidade de São Paulo (Bolsa FAPESP), tendo se formado mestre em música (Bolsa CAPES, 2009-11) e bacharel em composição (2005), na mesma instituição. Como compositor, já participou de festivais importantes, como a Bienal de Música Contemporânea (RJ) e teve peças executadas nos EUA e Coreia. Seus mais recentes trabalhos lançados foram: o CD/DVD Olhando pra Lua: tributo a Luiz Gonzaga (2013), do grupo regional Bicho de Pé, e o CD Num dia, no outro (2012), do grupo de câmara Seis com Casca - ambos selecionados para o Prêmio da Música Brasileira. Em sua carreira, constam turnês pelo Brasil, Europa e Estados Unidos, nas diversas áreas em que atua. 